\title{
Snow Facies Over Ice Sheets Derived From Envisat Active and Passive Observations
}

\author{
Ngan Tran, Frédérique Rémy, Hui Feng, and Pierre Féménias
}

\begin{abstract}
This paper aims to separate different snow regions over the terrestrial ice sheets based on their measured microwave signatures. It takes advantage of coregistered data from passive and active sensors on the Environmental Satellite (Envisat) to directly derive a snow facies indicator in a point-by-point basis. This paper represents the first attempt of this kind in exploiting nadir-viewing and dual-frequency data from both altimeter and radiometer sensors. The approach is based on a clustering method. Such representation of the data by means of fewer clusters necessarily loses fine details but achieves simplification in geographical representation and eases the description of the condition of the ice sheets in 2004. Our approach broadens the description of the snow pack by taking into account characteristics such as surface roughness, grain size, stratification, and snowmelt effects, whereas the latter has often solely been considered in most previous work. Such partition of the ice sheets might help to better understand relationships between microwave signatures and snow morphology. It could also be useful for estimating elevation uncertainty in altimeter data, which, in turn, is essential to correctly interpret the significance of the rates of elevation change in a changing climate and to convert elevation change to snow mass change.
\end{abstract}

Index Terms-Pattern classification, radar altimetry, snow.

\section{INTRODUCTION}

$\mathbf{S}$ ATELLITE altimetry represents a major tool to better understand ice sheet behavior and to monitor changes in ice sheet height, thickness, and mass balance as effects of climate changes. Indeed, the accuracy of the height measurements has allowed the construction of precise topography [1]-[3], except in steep marginal zones. This knowledge enables the survey of the temporal height variations and, thus, the estimation of their mass balance and of their flow [4]-[10]. However, a comparison between altimeter radar and ICESat laser retrieved elevations has showed that the radar precision varies from $59 \mathrm{~cm}$ to $3.7 \mathrm{~m}$ for ERS-2 and from $28 \mathrm{~cm}$ to $2.06 \mathrm{~m}$ for Environmental Satellite (Envisat) [11]. These results show that, despite the invaluable nature of the altimeter measurements, there are still some unresolved aspects that need to be addressed.

Manuscript received November 21, 2007; revised April 16, 2008. Current version published October 30, 2008. This work was supported by the European Space Agency.

N. Tran is with Collecte Localization Satellites, Space Oceanography Division, 31520 Ramonville St-Agne, France (e-mail: ntran@cls.fr).

F. Rémy is with the Laboratoire d' Etudes en Géophysique et Océanographie Spatiales, 31400 Toulouse, France.

H. Feng is with the Ocean Process Analysis Laboratory, University of New Hampshire, Durham, NH 03834 USA.

P. Féménias is with the Ground Segment Department, Earth Observation Programs Directorate, European Space Agency, 00044 Frascati, Italy.

Color versions of one or more of the figures in this paper are available online at http://ieeexplore.iee.org.

Digital Object Identifier 10.1109/TGRS.2008.2000818
These remaining uncertainties in estimating the correct height arise because of the Ku-band radar wave $(13.6 \mathrm{GHz})$ penetration within the cold and dry snow medium and of its dependence on snow pack characteristics that, in turn, display seasonal and spatial variability [12]-[16]. Indeed, the metamorphosis of snow and firn is closely related to regional climate conditions: air temperature, wind, accumulation rate, and intensity of summer melt, which are governed by geographic location, surface slope, elevation, orographic effects (i.e., relief effects), and surface undulations. Depending on the interplay between these factors that introduce spatial and temporal variations in snow pack genesis, distinct snow morphologies arise, and they can be classified according to snow facies.

The variability in the radar penetration depth causes incorrect interpretation of altimetric data series and represents the current limit for the ice sheet mass balance estimation. Moreover, it is also difficult, nowadays, to separate the climatological longterm trend on ice thickness changes from the artificial trend due to fluctuations in the snow pack characteristics related to snow pack compaction and firn densification. A change in snow density or in snow stratification (e.g., due to an increase in the number of ice layers) causes an elevation change without a corresponding change in snow accumulation [17] and, so, in mass. Thus, various aspects involved in the estimation of the uncertainty in the altimeter elevation measurement and the conversion from elevation change to snow mass change would all benefit from a better description of snow facies regions and characteristics. Knowledge of their spatial extents and monitoring of the variations of the geographical position of the snow zone boundaries are important in assessing the significance of the rates of elevation change across the different snow zones delimited by topography and local climate differences and throughout different times of the year. The precise surveying of ice thickness over ice caps requires a better understanding of the relationships between the resulting observed altimeter echoes and snow characteristics.

In this paper, we present a classification of snow facies based on passive and active microwave sensors. These results will permit more accurate determination of ice sheet mass balance by proper interpretation of the altimetry data and provide the potential to more efficiently monitor the effects of climate change on the ice sheets of Greenland and Antarctica. Indeed, they are considered as sensitive key indicators of global climate change.

The subdivision of an ice sheet into snow facies was originally conceived by Benson [18] based on field observations from snow pits and cores in the western part of the Greenland ice sheet. He had defined a sequence of four snow facies: 1) the 
dry snow zone; 2) the percolation zone; 3 ) the wet snow zone; and 4 ) the bare ice (or ablation) zone. Since the publication of his classification scheme, many investigators have associated features in satellite remote sensing data with some or all of these snow zones, depending on what may be imaged by various types of satellite sensors (scatterometer, off-nadir radiometer, synthetic aperture radar, etc.). Most of these works on melt detection topic have been done over Greenland [19]-[25]; a few have concerned Antarctica [26], [27]. Characterization of the microwave signatures over ice sheets by a coherent delineation of the different snow facies represents a thoughtful tool for tracking the effects of climate change, as shown by these numerous works on melt detection.

The complementarities of passive and active microwave measurements have been put forward in past works studying snow and ice aspects [22], [27]-[30]. Water content, snow density, grain size, stratigraphy, and surface roughness of the snow pack have an effect on both the surface and the volume backscatter strength of the radar signal [19], [31] and contribute to the change in emissivity and, hence, in brightness temperatures [31], [32]. Since the different instruments rely on different physical mechanisms to observe the snow pack, no single one is the solution to all problems. Coregistered measurements from the altimeter and radiometer, as provided by Envisat, offer a great opportunity for developing snow facies indicator in a point-by-point basis but would also allow operational long-term monitoring. The approach presented here is in the preliminary stages of assessment but could be ultimately applied to the Global Monitoring for Environment and Security Sentinel-3 mission planned for launch in the 2011-2012 timeframe.

In Section II, important background information is provided. Envisat data are presented, along with a review of the snow characteristics and associated basic microwave signatures. Section III introduces the clustering technique that will be used to objectively partition each ice sheet into several regions. The classification results over Greenland and Antarctica are presented in Sections IV and V, respectively. Since we use an unsupervised classification scheme for the analysis, highlights will be put on which snow features can be exactly retrieved from the combination of the two Envisat sensors data and whether the resulting regions partition could be related to zones, as defined by [18].

\section{BACKGROUND}

\section{A. Envisat Microwave Sensors}

The Envisat platform was launched on March 2002 and carries ten different sensors. The satellite orbit is sun-synchronous at an altitude of $800 \mathrm{~km}$, with an inclination of $98.55^{\circ}$, allowing measurements over the polar ice sheets of up to $81.5^{\circ} \mathrm{N}$ and $\mathrm{S}$, with a 35-day repeat cycle and a three-day repeat subcycle. Among the different sensors are a radar altimeter (socalled RA-2), which is derived from the ERS-1 and ERS-2 altimeters [33], and a microwave radiometer (MWR). Unlike its predecessors, RA-2 is a dual-frequency radar that operates not only in the Ku-band $(13.575 \mathrm{GHz})$ but also in the S-band (3.2 GHz). The conversion of its raw measurements into geo-
TABLE I

CORRESPONDENCE BETWEEN THE ENVISAT CYClE Number AND THE DATE PERIOD

\begin{tabular}{|c|c|}
\hline Cycle \# & Time period \\
\hline 23 incomplete & $01 / 01 / 04-02 / 02 / 04$ \\
\hline 24 & 03/02/04-08/03/04 \\
\hline 25 & 09/03/04-12/04/04 \\
\hline 26 & $13 / 04 / 04-17 / 05 / 04$ \\
\hline 27 & $18 / 05 / 04-21 / 06 / 04$ \\
\hline 28 & $22 / 06 / 04-26 / 07 / 04$ \\
\hline 29 & $27 / 07 / 04-30 / 08 / 04$ \\
\hline 30 & $31 / 08 / 04-04 / 10 / 04$ \\
\hline 31 & 05/10/04-08/11/04 \\
\hline 32 & 09/11/04-13/12/04 \\
\hline 33 incomplete & $14 / 12 / 04-31 / 12 / 04$ \\
\hline
\end{tabular}

physical quantities through retracking algorithms is done completely on-ground. Four different retrackers (called ocean, ice1, ice2, and sea ice, respectively) are simultaneously run to let the users choose the most suitable for their own application. Only the backscatter cross sections (denoted as $\sigma_{0}$ ) will be used hereinafter.

Concerning the MWR, it is also a dual-frequency sensor that measures at 23.8 and $36.5 \mathrm{GHz}$. It has the same concept and specifications as the two ERS MWRs. It is a Dicke radiometer, near-nadir viewing with offset parabola antenna and with one feed horn for each frequency. The instrument configuration is given such that the $23.8-\mathrm{GHz}$ channel is pointing in the forward direction, with the footprint center at $25 \mathrm{~km}$ from the nadir, whereas the $36.5-\mathrm{GHz}$ channel is in the backward direction, with the footprint center at $35 \mathrm{~km}$ from the nadir position. The two radiometric measurements are geolocated with the altimeter measurements in the delivered products. Its primary mission is the determination of the tropospheric water vapor path delay correction for RA-2 over the ocean, but its two brightness temperature (TB) measurements are provided everywhere. This allows additional application of MWR data over continental areas and, particularly of great interest, hereinafter, over polar ice sheets. We use the standard Geophysical Data Record product over the year 2004, corresponding to cycles $023-033$. Table I provides the correspondence between cycle number and time period to ease future interpretations of seasonal variations in classification results. More details can be found in the product handbook [34]. The different maps shown in the following are in a polar stereographic projection, with reference to the WGS94 ellipsoid. The use of coregistered data collected from dual-frequency active/passive nadirlooking instruments should increase the level of information that can be exploited for the partition of the ice sheets into regions.

\section{B. Review of Snow Metamorphosis and Benson's Snow Facies}

Snow studies on Greenland and Antarctica have shown that the snow pack consists of a seasonal alternation of successive snow layers with different densities, surface roughness, and ice grain sizes. The snow characteristics of each summer or winter layers primarily depend on the atmospheric conditions occurring at the deposition time and are connected to the wind, temperature, snow accumulation, or rates of snow drift. The 
interplay between these factors is variable, and the metamorphism of the snow grain size is a complex phenomenon. The newly formed grain size primarily depends on temperature and then progressively grows with time [35] and, then, with depth. In fact, there are two principal physical phenomena that have opposite effects on the grain size in the surface layer. High surface temperatures cause the snow grains to grow larger, whereas high accumulation rates bury them quickly; the grains at the surface are thus small, because they are newly formed. Moreover, the katabatic wind may crush the snow grains [36] and create smaller grains in low-accumulation regions. They also carve the surface at the centimetric scale (microroughness) and at the metric scale (sastrugi or erosional snow features), produce snow drift, and contribute to erosion via sublimation processes. All these factors shape a snow layer and act therefore mostly at seasonal scale and thus participate to the internal snow stratification. Due to the radar wave penetration, it is the snow characteristics in the first few meters of firn that play a significant role on the radar observation. Additionally, occurrences of melt events modify the snow pack characteristics in different regions. These changes form the basis of Benson's snow facies discrimination. A comprehensive review of the snow metamorphosis related to Benson's snow regions is provided hereinafter as a reminder. This will ease the interpretations of the results presented in Section IV over Greenland to validate our approach.

Benson has defined a sequence of four snow facies: 1) the dry snow zone; 2) the percolation zone; 3 ) the wet snow zone; and 4) the bare ice (or ablation) zone. He located the dry snow zone on the highest parts of Greenland, where melting is supposed to never occur even during the summer warming. The prevailing dry snow metamorphism thus depends on the gradual compaction due to its own weight by gravity and wind action, recrystallization, and depth hoar development due to internal temperature and moisture gradients. Owing to the absence of melt events, the upper part of the dry snow zone has a low snow density, uniform crystals of small grain size, and a moderately layered snow pack without melt-related ice layers. However, diagenetic changes in the structure of snow and firn can take place without melt. They are accelerated with higher temperatures until a point at which melting may take place. In fact, when summer temperatures in the upper snow pack increase above $-10{ }^{\circ} \mathrm{C}$, there is a significant increase in the vapor pressure of ice. In firn strata, this can lead to vapor transport and sublimation. The net result is the destruction of original precipitated snow-crystal forms, increased grain size, and increased bonding between grains. These changes in snow and firn are common to the spring and summer months in the dry snow zone.

Downslope from the dry snow zone is the percolation zone. In this zone, as summer surface-air temperatures increase, diagenesis much more rapidly and dramatically takes place by melting. Surface melt water percolates principally downward but can occasionally laterally spread out when it encounters a relatively impermeable layer. When the vertical percolated water reaches a depth where temperatures are below $0{ }^{\circ} \mathrm{C}$ or when cooling episodes occur in the upper portion of the snow pack, the free water refreezes, and fingerlike structures (known as ice pipes or glands) are formed. In cases where water laterally spreads, when it refreezes, it forms horizontal ice lenses. The percolation zone is thus characterized by large grain sizes due to the sublimation associated with melt and numerous subsurface ice pipes and lenses caused by melt-freeze cycles.

At lower altitudes, in the wet snow zone, the snow mass reaches the melting point, and free water is present throughout the upper snow pack. Ice lenses and pipes are still present in the wet snow zone. The elevated temperature enhances compaction and causes the firn to be denser than that in the percolation zone. In general, surface melting is intensive, and the wet snow zone is damp throughout the summer season. At latitudes below along the margins of the ice sheet is the bare ice zone, where all the winter snow accumulation melts and leaves the ice sheet as runoff, exposing the underlying ice. Due to intensive melting, the ice layers in this zone have merged into a continuous ice mass by freezing melt water. This ordered sequence of four snow zones characterizes better Greenland than Antarctica snow packs [37], [38]. Such discrimination has been the main focus of numerous works since it can provide inputs on climate change analyses.

Indeed, the differentiation between the percolation zone and the wet snow zone, for instance, is valuable for investigating the mass balance and stability of the glacial system, mainly for the Greenland ice sheet. In the case of the percolation zone, the redistribution of melt water is horizontally and vertically limited near the surface; thus, melt processes yield no mass loss for the ice sheet and ice shelves. In contrast, melt water produced in the wet snow zone can potentially be discharged from the ice sheet to the sea, resulting in a net loss of mass [7]. Additionally, snowmelt that percolates down to the base of the ice sheet provides a lubricant between the ice sheet and the underlying ground surface, which enhances basal sliding and accelerates the flow of ice toward the margins of the ice sheet and out into the surrounding ocean [39].

The mapping of the dry snow and ablation zones is also important for defining the spatial extent of snow accumulation versus melt over the entire ice sheet to help estimate the net effect of these processes on mass balance, particularly for the Greenland ice sheet. For these purposes, microwave measurements of brightness temperatures and the backscatter cross section at off-nadir incidence angles were proven to be excellent tools for estimating melt occurrences, extent, and duration since the introduction of even small amounts of liquid water into the snow pack dramatically impacts the electrical properties of the snow for these probing frequencies [21], [40], [41]. This results in large changes in the microwave measurements of the surface, enabling melt detection. In fact, the sensitivities of microwave measurements to other characteristics of the snow pack, such as the presence of liquid water, allow finer partition of the snow pack to better describe its actual condition. In particular, Long and Drinkwater [19] were able to discriminate two subregions within the Benson's dry snow zone of Greenland by interpreting scatterometer signatures. The next section reviews known dependencies of microwave signals on snow pack characteristics to facilitate forthcoming interpretation of the results presented in Sections IV and V. 


\section{Microwave Signatures From Snow Pack}

The behavior of the microwaves in the snow pack is, in fact, not very well known because of the complexity of the medium, the large number of involved parameters, and the lack of dense sampling of the ice sheet by in situ measurements. Due to the wave penetration within the snow pack, the altimeter echo is constituted by reflections from the air/snow interface and from the subsurface adjacent layers of ice grain interfaces. The surface component is controlled by the Fresnel coefficient and statistics of the surface roughness created by surface wind, whereas, inside the snow pack, the subsurface component depends on internal stratification and is attenuated by snow extinction (i.e., losses by absorption and scattering by ice pipes and lenses and by multiple reflections). The absorption coefficient depends on the radar wave and on the snow temperature, whereas the scattering coefficient depends on the scatter volume, i.e., the ice grain volume, and on the snow density. The penetration depends on the dielectric losses (absorption, scattering, and internal reflections), which are strongly frequency dependent. Therefore, the S-band wave is expected to more deeply penetrate the snow pack (tens of meters) than the $\mathrm{Ku}$ band wave (a few meters deep). The different frequencies look so at slightly different portions of the upper ice sheet.

Moreover, small-scale surface features, such as sastrugi and snow dunes, and medium-scale features, such as topography slopes and undulations, play a role in the altimetric return waveforms because of the induced variations of the illuminated radar footprint and of its orientation with respect to the antenna direction. The topography effect mostly consisting of the slope effect is modulated by the antenna pattern gain that depends on the square of the frequency, so that the S-band backscattering is strongly less affected than the $\mathrm{Ku}$-band backscattering. Therefore, the radar backscattering is not only influenced by the physical properties of the snow pack but also distorted by the topographical effects, which complicate the recognition of snow zones because of the geographical correlation.

The presence of liquid water in snow changes the dielectric properties of snow and ice so significantly that it increases surface reflection and limits the contribution of subsurface or volume-scattering effects by absorption and extinction within the upper layers [42]. During the summers, the penetration depth of the radar signal is dramatically reduced from several meters to the uppermost $3-4 \mathrm{~cm}$. As reviewed, spatial and temporal variabilities in the backscatter cross section depend on numerous factors with combined effects, and it is thus difficult to separate each one to quantify its impact.

Concerning the brightness temperature at microwave wavelengths, TB is a function of the physical temperature of the near-surface snow times its emissivity [43], according to the Rayleigh-Jeans approximation. Emissivity of snow is influenced by snow characteristics, such as grain size, density, and crystal structure [32]. Nonetheless, TB is dominantly forced by the seasonal air temperature cycle, as shown by their high correlations with in situ [44], [45] and reanalysis records of surface temperature and by radiative transfer modeling studies [26], [46]. Depending on their frequency, TBs are correlated to the temperature of a layer of snow at different depths near the surface. The radiation at lower frequencies is emitted by deeper layers that are less affected by seasonal changes. However, variations in snow surface properties related to snow accumulation also contribute to the variation in the emissivity. As Zwally and Fiegles [32] noted, repeated meltings and refreezings of snow grains near the surface increase the grain size, leading to more radiative scattering and lower emissivity and TB. In the opposite sense, a high snow accumulation rate leads to the continuous formation of new lower density snow layers with small grain sizes, which have higher TB. The separation of accumulation and air temperature effects on TB is still difficult.

As for backscattering, microwave emission is strongly sensitive to the presence of water in snow. A sharp increase in emission is observed with even a small amount of water content. Passive microwave data have widely been used to study the onset, duration, and extent of melt on the Greenland ice sheet [22], [24], [25], for instance.

The major difficulty in the interpretation of microwave signatures from snow pack lies in the fact that no sensor is sensitive to a unique snow characteristic. Indeed, the brightness temperature, as measured by the passive sensors, or the radar backscattering, as measured by the active sensors, are at different levels and affected by many parameters, such as snow grain size, stratification, surface wind roughness, snow temperature, wetness, and density. In particular, the active sensor is more sensitive to surface roughness than the passive sensor, which shows, in turn, a higher sensitivity in temperature. The combined use of these two types of measurements might provide, for the first time, an empirical discrimination between the different effects.

The metamorphosis of snow and firn is strongly controlled by the amount of snow accumulation, seasonal surface temperature, and the intensity of summer melt, which, in turn, spatially vary with location, surface elevation, and regional climate. The different information thus displays strong geographical correlations. Seasonal variation is clearly evident in backscatter and brightness temperature behaviors when comparing those over Greenland [Fig. 1 (top and bottom)] and those over Antarctica [Fig. 2 (top and bottom)]. The top panels illustrate a winter situation, whereas the bottom panels display a summer situation. We have plotted Ku-band backscatter, its difference with S-band backscatter and brightness temperature average and ratio (see Section III-B. for details). The potential advantages of such dual-frequency measurements have been analyzed in past studies. For instance, Surdyk and Fily [47] reported that the gradient ratio of brightness temperatures between the two ERS-1 radiometer frequencies is linked to snow grain size. On the other hand, differences in the dual-frequency backscatter, as measured by the scatterometer, are reported to have two causes: 1) The surface centimeter-scale roughness is differently seen by the $\mathrm{Ku}$ - and $\mathrm{C}$-bands (i.e., smoother in the C-band). 2) Because the $\mathrm{C}$-band wave penetrates deeper, the snow layering and buried ice inhomogeneities affect the $\mathrm{C}$-band signals more than the Ku-band signals. Moreover, the snow grains are electrically larger at the $\mathrm{Ku}$-band, corresponding to a larger sensitivity to volume scattering from recently accumulated snow [48]. These results based on the interpretation of scatterometer data are applicable for Envisat dual-frequency altimeter measurements 
(a)
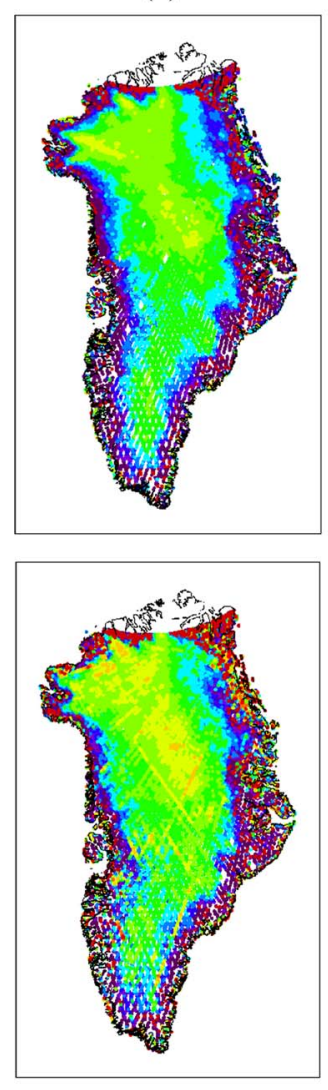

(b)
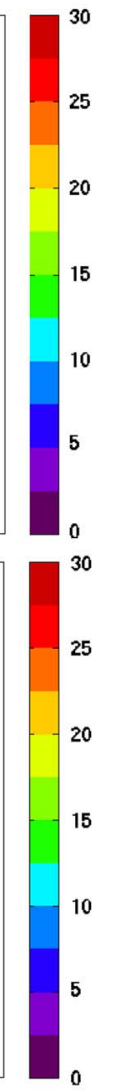
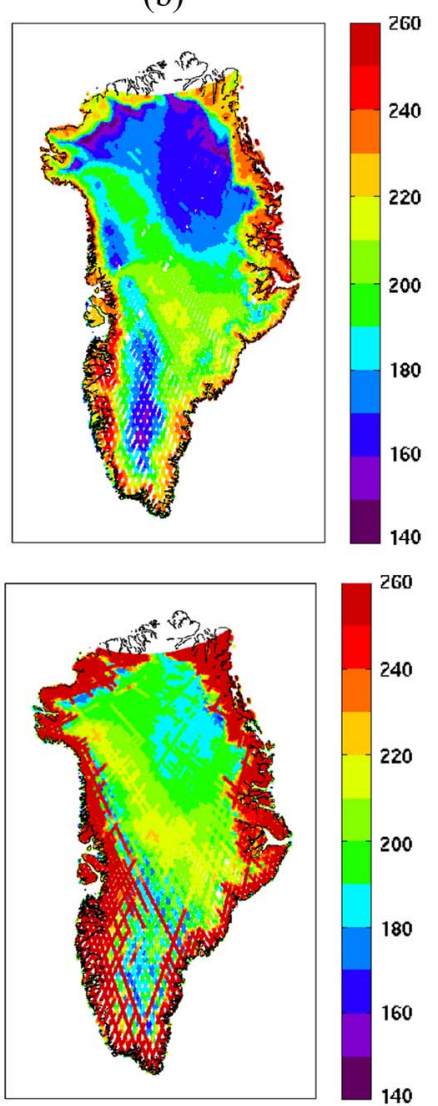

(c)
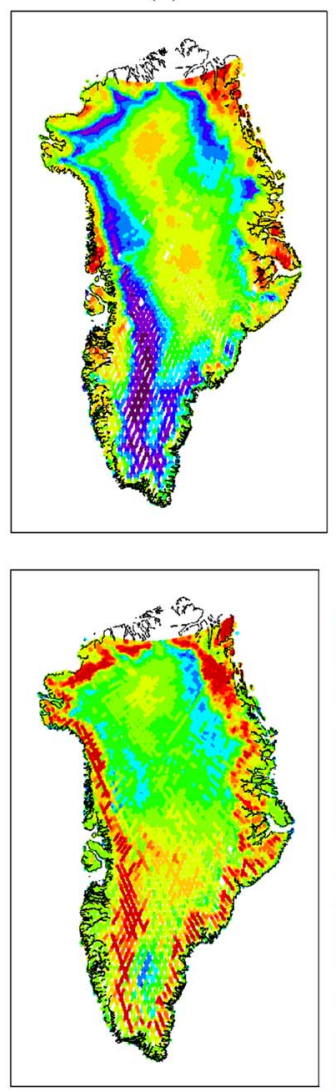

(d)
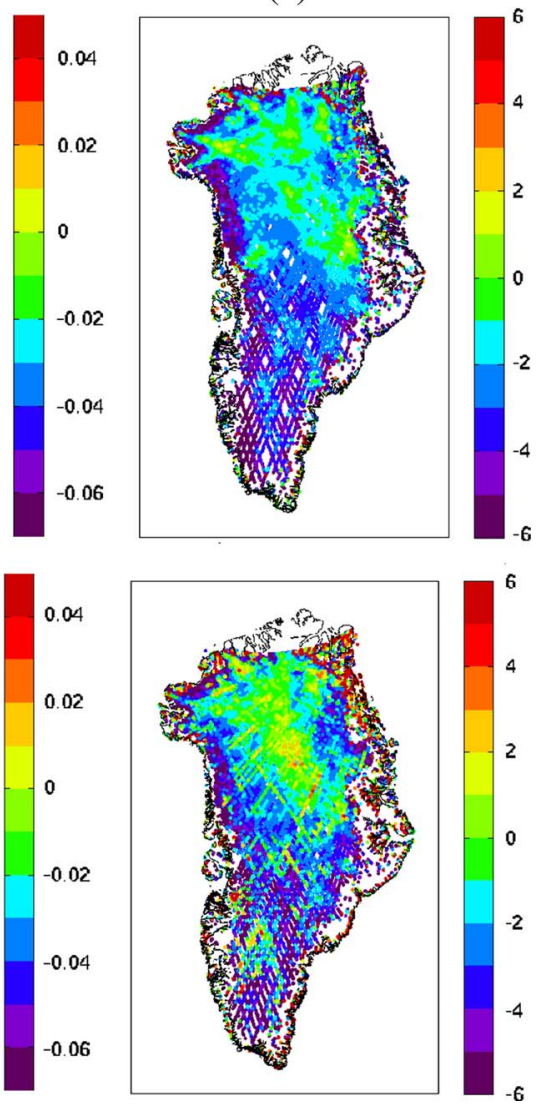

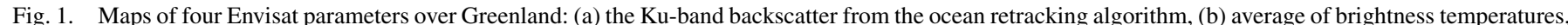
(c) brightness temperature ratio, and (d) difference between $\mathrm{Ku}$ - and S-band backscatter. (Top) Winter microwave signatures from cycle 023 data. (Bottom) Summer microwave signatures from cycle 029 data.

(a)
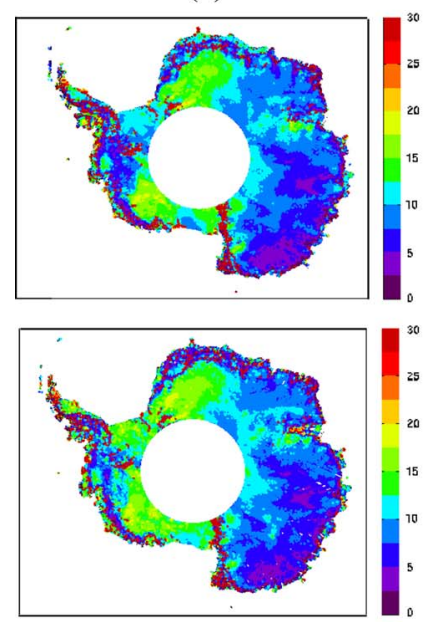

(b)
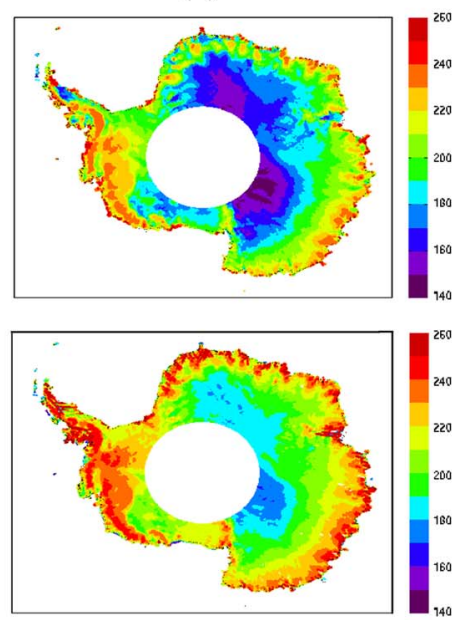

(c)
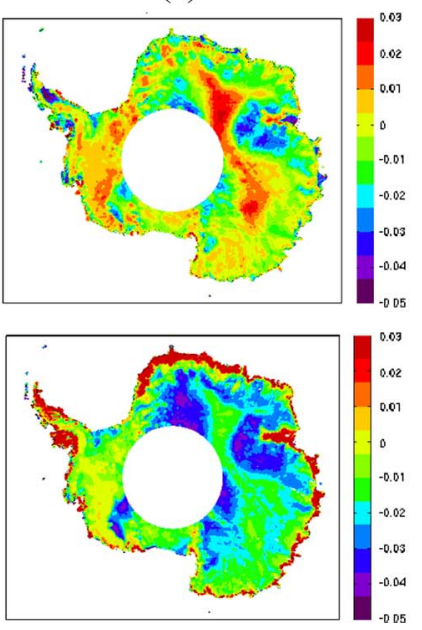

(d)
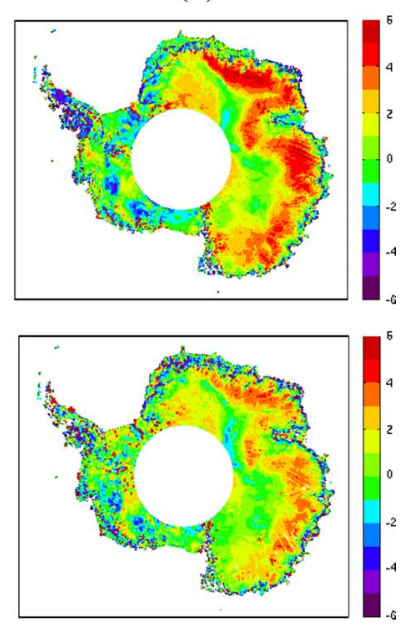

Fig. 2. Maps of four Envisat parameters over Antarctica: (a) Ku-band backscatter from the ocean retracking algorithm, (b) average of brightness temperatures, (c) brightness temperatures ratio, and (d) difference between $\mathrm{Ku}$ - and S-band backscatter. (Top) Austral winter microwave signatures from cycle 029 data. (Bottom) Austral summer microwave signatures from cycle 023 data.

since the S-band wave characteristics are close to the C-band wave characteristics [49].

In the absence of melting, the microwave scattering and emission properties of the large ice sheets are rather stable in time. The snow pack is completely frozen and holds stable conditions particularly during winter. Over Antarctica, summer warmth is short lived in December and January, whereas winter remains cold for four to five months.

Correlations between features from Envisat data maps (Figs. 1 and 2), with global maps of elevation, slope, accumulation, surface temperature, and wind field, are complicated to analyze due to the interplay and to the geographical correlations 
between these different factors. However, in some particular areas, strong correlations between these factors can be observed. Indeed, in the innermost portion of the Antarctic ice sheet, for instance, the high surface elevation is associated to a very low surface slope, the coldest surface temperature, low wind conditions, and low snow accumulation, whereas a combination of opposite extremes is observed near coasts. The unsupervised clustering scheme used in the following is expected to help such correlative analysis by simplifying the geographical mapping and highlighting homogeneous areas within the whole ice sheet.

\section{Methodology}

Clustering is a division of data based on features. Each group, which is also called a cluster or class, consists of data points that have similar features between themselves and that are dissimilar to data points in other clusters. Representing data by fewer clusters necessarily loses certain fine details but achieves simplification. However, the clusters in the data are usually not completely well separated. Fuzzy clustering is a popular method that deals with this aspect. It computes gradual memberships, thus offering the opportunity to deal with data that belong to more than one cluster at the same time by assigning to each data point degree of membership to all classes. This method has been widely used in remote sensing applications [50]-[52].

Most fuzzy clustering algorithms are based on an objective function. They determine an optimal classification by minimizing this function, where each cluster is represented by a tie point or cluster center. The degrees of membership to which a given data point belongs to the different clusters are computed from the distances of the data point to the different tie points. The closer to the center of a cluster a data point lies, the higher its degree of membership to this cluster. Among the fuzzy methods, the fuzzy $c$-means (FCM) iterative clustering algorithm is, by far, the most popular and is frequently used in pattern recognition [53].

In the following, unsupervised classification based on the FCM clustering algorithm is applied to the Envisat data. The algorithm is unsupervised in the sense that we do not know the tie-point locations a priori and, therefore, the different classes. It generates, nevertheless, a classification of the data into a prespecified fixed number of clusters. Ideally, this number $c$ should correspond to the number of substructures that are naturally present in the data. Section III-A presents an overview of the FCM clustering method, and Section III-B presents the development of Envisat classifiers.

\section{A. FCM Clustering Method}

Each classifier is developed based on a data set that has $N$ data points $\left\{\overrightarrow{x_{1}}, \ldots, \overrightarrow{x_{N}}\right\}$ that are individually described by $P$ features. The data set consists though of an $N * P$ matrix. The FCM clustering algorithm will partition this collection of data points into $c$ clusters, each named "class $i$," with $i$ ranging from 1 to $c$, and will find a cluster center, i.e., a $P$-dimensional tiepoint vector $\vec{\nu}_{i}$, in each group. The locations of the cluster centers are iteratively adjusted after a randomized initialization and until the optimization criteria are met by minimizing the objective function $J$ given by

$$
J=\sum_{i=1}^{c} \sum_{k=1}^{N} u_{i k}^{m} d_{i k}^{2}=\sum_{i=1}^{c} \sum_{k=1}^{N} u_{i k}^{m}\left\|\overrightarrow{x_{k}}-\overrightarrow{v_{i}}\right\|^{2} .
$$

In (1), $u_{i k} \in[0,1]$ represents the membership degree of data point $\overrightarrow{x_{k}}$ in "class $i$ " represented by its center $\vec{\nu}_{i}$ and satisfies the following constraint:

$$
\sum_{i=1}^{c} u_{i k}=1 \quad \forall k=1, \ldots, N .
$$

$c$ and $m$ are two parameters that need to be specified before running the algorithm. $m$ is a weighting exponent that controls the fuzziness of the method. This parameter states how many the clusters are allowed to overlap. $d_{i k}^{2}$ in (1) is the squared Euclidean distance between data point $\overrightarrow{x_{k}}$ and tie point $\overrightarrow{v_{i}}$. At each iteration, the following two functions are updated in order for $J$ to reach a minimum and in order to calculate optimized membership matrix $\mathbf{u}$ and cluster tie-point coordinates matrix v:

$$
\begin{aligned}
\overrightarrow{v_{i}} & =\frac{\sum_{k=1}^{N} u_{i k}^{m} \overrightarrow{x_{k}}}{\sum_{k=1}^{N} u_{i k}^{m}} \quad \forall i=1, \ldots, c \\
u_{i k} & =\frac{1}{\sum_{j=1}^{c}\left(\frac{d_{i k}}{d_{j k}}\right)^{2 /(m-1)}} \quad \forall i=1, \ldots, c \text { and } \forall k=1, \ldots, N .
\end{aligned}
$$

The iteration process stops when there is not much improvement between two iterations.

\section{B. Envisat Classifier Development}

Fuzzifier $m$ is an important parameter for FCM. Most of the literatures recommend choosing an $m$ of about 2. It is, here, set to 2 . During the analysis, we have computed different solutions by changing the number of class $c$ from 3 to 8 to look at how the different highlighted regions change when we search for more partitions within the snow pack. By this way, we compensated for missing a priori knowledge about the class number. With this fuzzy approach, each data point is bound to each cluster by means of a membership whose value varies between 0 and 1 and which represents the fuzzy behavior of the algorithm. However, due to the high potential number of possible derived classes and mixed groups and in order to validate the approach in a simpler configuration, we interpret at the present time the results in a "hard" partition way by using, for each data point, only the highest membership value to retrieve its "dominant" class. Interpretation of the fuzzy behavior is left for a future paper. Note that our main goal is not to calibrate our classifier to retrieve exactly the Benson's snow facies but to explore the potential of Envisat measurements. Our classification results will however be compared with such defined snow zones.

The two ice sheets will separately be analyzed hereinafter. Antarctica's climate is colder and more stable than that of Greenland and is largely a dry snow zone. This difference is due to the more varying climate of the Arctic region, which 
is related to the higher frequency of cyclones delivering warm moist air and precipitation to the ice sheet [54]; and because the imposed changes of the forcing boundary conditions (e.g., sea surface temperatures) are more important [7]. The number of facies has been determined during the scope of the analysis, along with the selection of the Envisat parameter set to be used in order to well separate different zones. We present hereinafter only one of those solutions over each ice sheet. Different tests of the combinations of Envisat parameters were performed but are not shown here as well.

We applied the FCM classification to subsets from the Greenland and Antarctica global year-2004 data sets to calibrate the two algorithms. These subsets are composed of data from two cycles, i.e., 023 and 029, to represent a winter (austral summer) and a summer (austral winter) condition for Greenland (Antarctica). Hereinafter, the focus will be put on solutions based on the combinations of the following four features as input parameters for a pixel $k$ :

1) $x_{1 k}=$ Ku-band $\sigma 0$

2) $x_{2 k}=$ average of TB;

3) $x_{3 k}=$ ratio of TB defined as $\quad$ (TB_23.8 - TB_36.5)/ (TB_23.8 + TB_36.5);

4) $x_{4 k}=\sigma 0$ difference defined as $(\mathrm{Ku} \sigma 0-\mathrm{S} \sigma 0)$.

These parameters form a set of parameters derived from both the Envisat RA-2 and MWR sensors and take advantage of their dual-frequency measurements. We based our analysis on parameters derived from the ocean retracking since this algorithm appears to provide slightly more coverage of the ice sheets (mostly in the marginal regions of the ice sheets) than the other available retracking algorithms due to convergence difficulties, as indicated by the measurement confidence data flag. Note that the different retracking algorithms display globally similar geographical features in both the Ku- and S-band maps (Figs. not shown).

The different parameters are, of course, correlated to some degree since they are affected by the same snow pack characteristics but at different levels of dependence. The information they encompassed is therefore not fully redundant and should help to more finely discriminate the snow regions. These partitions are geophysically interpreted in terms of spatial and temporal variability.

As previously mentioned, we tested the class number by fixing it from 3 to 8 before applying the classification algorithm on each data subset. The results (not shown) yield close general patterns in the distribution of the classes, depending on the number of classes fixed a priori. The higher the class number, the smaller each class extent; thus, a finer gathering of the data points is performed, which is linked to a more detailed discrimination of the snow pack characteristics. The contours of the classes are seen to delineate rather large spatially coherent regions. We think that solutions formed with six and seven classes provide interesting partition of Greenland and Antarctica, respectively. Note that it is difficult to validate such choice since it is based on intuitive interpretations from our understanding of their spatial and temporal behaviors. Nonetheless, such results should help to better understand relationships between the microwave signatures and the snow pack properties
TABLE II

STATISTICAL INDICATORS (MEAN AND STANDARD DEVIATION) OF THE Four ENVISAT QuANTITIES. THEY ARE COMPUTED OVER GREENLAND FROM THE DATA OF CYCLES 023 AND 029

\begin{tabular}{lcccc}
\hline & $\begin{array}{c}\text { x } 1=\text { Ku } \sigma 0 \\
(\mathrm{~dB})\end{array}$ & $\begin{array}{c}\mathrm{x} 2=\mathrm{TB} \_ \text {avg } \\
(\mathrm{K})\end{array}$ & $\begin{array}{c}\mathrm{x} 3=\mathrm{TB} \_ \text {ratio } \\
(/)\end{array}$ & $\begin{array}{c}\mathrm{x} 4=(\mathrm{Ku}-\mathrm{S}) \sigma 0 \\
(\mathrm{~dB})\end{array}$ \\
\hline mean & 10.9364 & 191.1737 & -0.0129 & -3.2148 \\
std & 5.7040 & 24.4632 & 0.0210 & 2.8027 \\
\hline
\end{tabular}

within identified homogeneous snow regions. Moreover, such classification might facilitate the extrapolation of local results from the comparison between satellite data and in situ measurements at snow pits and firn core drilling locations to a whole region. The next two sections present the results for the two selected solutions.

\section{Results Over the Greenland Ice Sheet}

\section{A. Comparison With Previous Partitions and Validation of the Approach}

The classifier input parameters can have very different ranges of variation, as shown in Table II. The preprocessing step of standardization is required to ensure that each data type is given appropriate weight in the classification. The standard approach is to shift and scale the data, so that each of the input parameters has zero mean and unit variance. These normalized data are denoted with a subscript $n$. Table II summarizes the statistical characteristics of the four input parameters computed from the two cycles used to normalize the data set, i.e., 023 and 029. By merging a winter and a summer cycle condition, these values take into account the full range of variations of these parameters. The results of its application on the time series of cyclic maps are provided in Fig. 3. They cover the whole year of 2004. As can be seen, geographical class distribution maps display stable spatial patterns in contiguous cycle periods during the freezing season. From the time series of maps and changes in the classes' distribution, three periods are identified: 1) the freezing winter season; 2) summer melting and ablation season; and 3) summer-fall transitional cooling period.

Our winter class distribution displays very close similarities with previous results based on scatterometer data. Indeed, a comparison with Long and Drinkwater's [19] results shows that our classifier delineates different snow zones, which can be related to the snow facies sequence defined by Benson: dry snow zone, percolation, wet snow, and ablation facies over Greenland.

The area defined by our class 5 (in red) is similar in shape to Long and Drinkwater's [19] dry snow zone I, the class 4 zone (in pink) is similar to their dry snow zone II, the class 2 zone (in light blue) is similar to the percolation zone, and our class 3 (in green) and 1 (in dark blue) zones seem to correspond to the wet snow zone and ablation zone with bare ice and/or land, respectively. Only our class 6 (in purple) does not correspond to the classes from these scatterometer results, as resumed in Table III. 

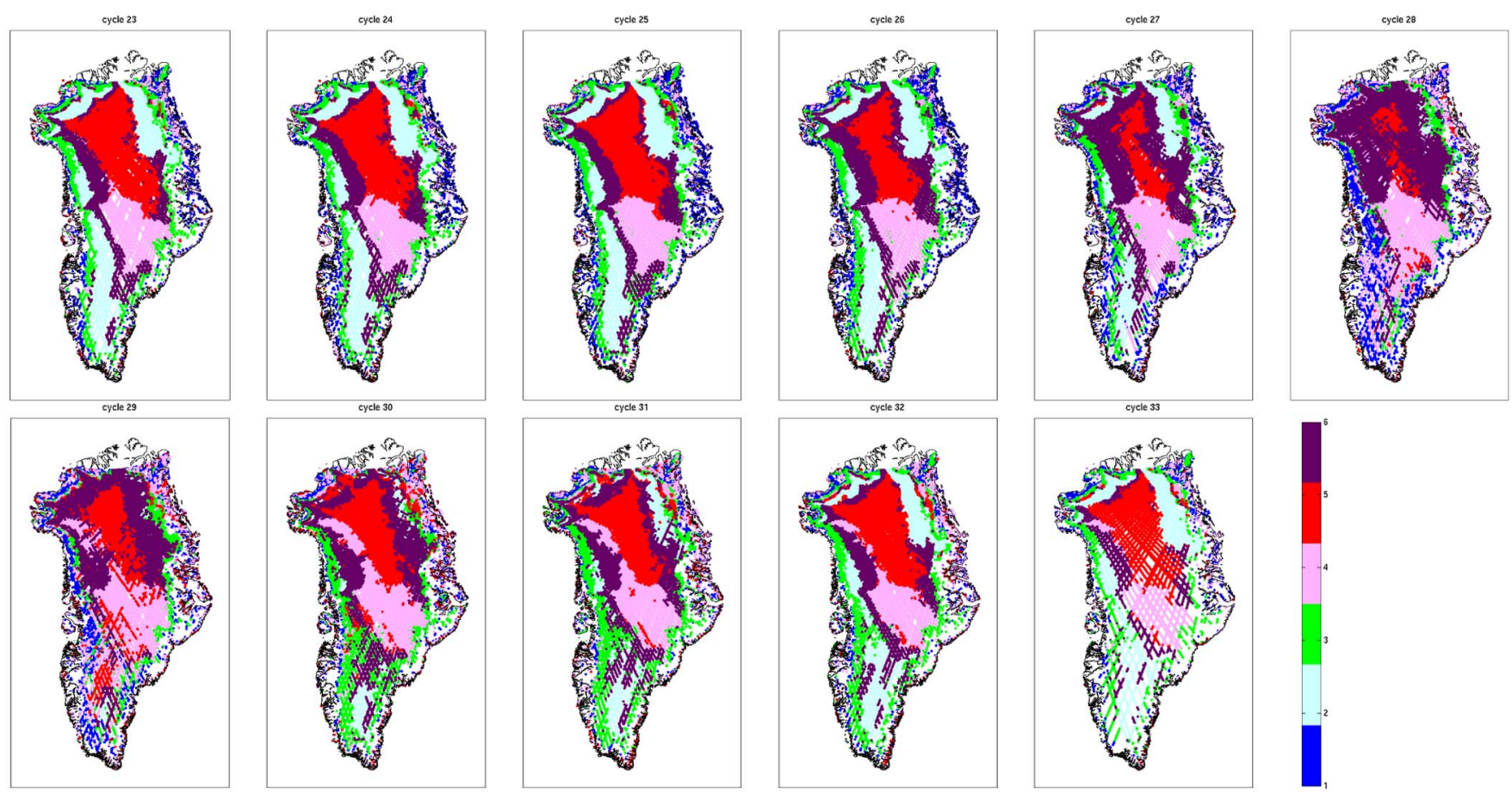

Fig. 3. Cycle summary of the Envisat snow classification algorithm based on six classes over Greenland. It covers the whole year of 2004 .

TABLE III

SYNTHESIS OF CLASS AND LABEL CORRESPONDENCE FOR THE GREENLAND PARTITION

\begin{tabular}{ccc}
\hline Class & Color & Label \\
\hline 1 & dark blue & ablation zone \\
2 & light blue & percolation \\
3 & green & wet snow \\
4 & pink & dry snow zone II \\
5 & red & dry snow zone I \\
6 & purple & intermediate dry / percolation \\
\hline
\end{tabular}

The diagram displayed in Fig. 4 shows a synthetic view of the positions of the cluster centers in the normalized 4-D space constituted by the set of the classifier input parameters. To ease the visualization, each parameter interval of variation is represented by a horizontal line, and the colored connections relate together the coordinates of each cluster tie point. As seen, for instance, the differences in signatures between the two dry snow zone classes (class 5 in red and class 4 in pink) are mostly due to the large differences in average TB and the backscatter difference. Indeed, these two signatures show the two largest relative separations, with the TB ratios for these two tie points being similar. The values for the coordinates of the class centroids in the 4-D input parameter space for the selected six-class solution are provided in Table IV.

The observed split into two subregions of the dry snow zone has previously been interpreted as being related to the annual accumulation that is closely dependent on precipitation and wind patterns across the ice sheet [19]. Indeed, low accumulation is observed in the low-elevation northeast region from the spine line of the ice sheet, whereas higher values are found

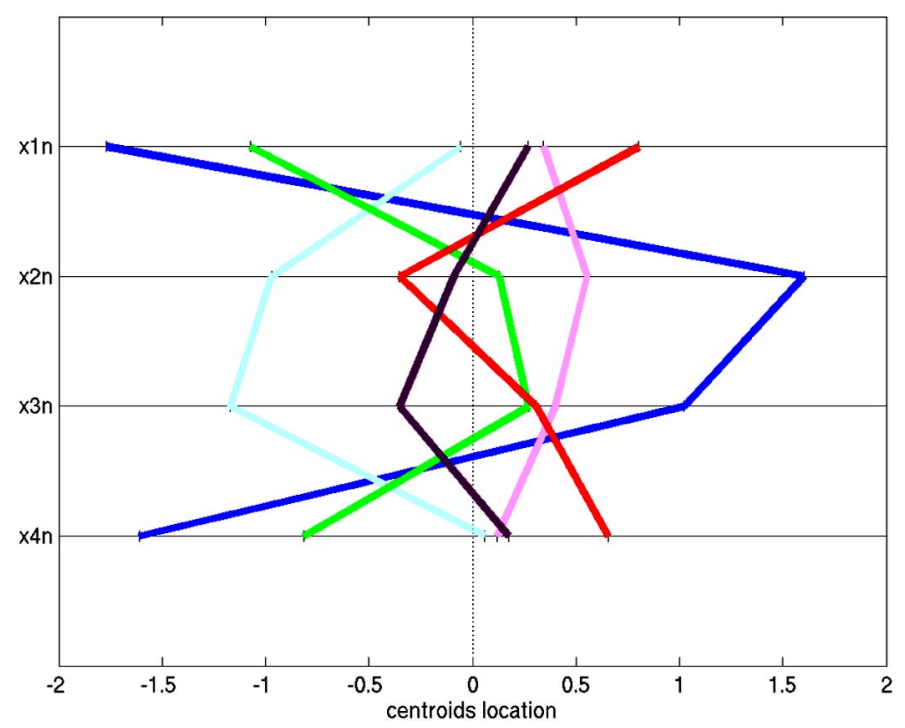

Fig. 4. Synoptic view of the tie-point locations. Each horizontal line represents the normalized variation interval of an input parameter. The segments in a given color connected the coordinates of a single tie point. The correspondence between classes and colors are as provided in the color bar in Fig. 3.

in the western flank and summit region [7]. Moreover, when moving south from the northeast dry snow zone, a decrease in the directionality of the surface roughness is observed via backscatter azimuth modulation change [55]. The location of this decrease corresponds to the windward side of the ridge running northeast from the summit. The reduction in the azimuth modulation in this area is attributed to a decrease in the katabatic wind flow due to the wind flowing cross- or upslope rather than downslope. Lower mean summer air temperatures, moreover, lead to slower grain growth and small grain size. Therefore, it is likely that a combination of differences in 
TABLE IV

TiE-Point Locations in the 4-D Normalized Space of the InPUT PARAMETERS FOR THE ENVISAT SNOW ClASSIFIER OVER GREENLAND. This Solution Is Composed of Six Classes

\begin{tabular}{lccccc}
\hline & color & $\mathbf{v}_{\mathbf{1 i}}$ & $\mathbf{v}_{2 \mathrm{i}}$ & $\mathbf{v}_{\mathbf{3 i}}$ & $\mathbf{v}_{4 \mathrm{i}}$ \\
\hline Class 1 & dark blue & -1.7687 & 1.6004 & 1.0223 & -1.6125 \\
Class 2 & light blue & -0.0572 & -0.9718 & -1.1724 & 0.0599 \\
Class 3 & green & -1.0752 & 0.1278 & 0.2710 & -0.8156 \\
Class 4 & pink & 0.3435 & 0.5521 & 0.4000 & 0.1178 \\
Class 5 & red & 0.8021 & -0.3529 & 0.3066 & 0.6574 \\
Class 6 & purple & 0.2705 & -0.0926 & -0.3545 & 0.1738 \\
\hline
\end{tabular}

both snow morphology and surface roughness might explain the difference of signatures between the southwestern and the northeastern dry snow zone [19].

This example clearly highlights the relationships between snow pack characteristics and microwave signatures. The time series of maps (in Fig. 3) from this six-class solution show that the warmer summer months (cycles 027-029) and the summer-fall transition (cycles 030-032) cause rapid changes in surface properties related to the melt process mainly in the southern part of the Greenland ice sheet, whereas the more northern perimeter regions display less fluctuations. Indeed, the area showing the most melt throughout the summer is the region along the west coast, beginning at the southern tip of the ice sheet and extending north past Jakobshavn. This region is the first to show melting and the last to show refreezing, and is wet, farther inland than most other locations. This may most likely be attributable to the low surface slope on the western side of the ice sheet, to the greater radiation intensity at the lower latitudes as compared to the higher ones, and possibly to the influence of the warm dry continental air mass coming from Canada, which dominates the summer circulation [56]. Another area of extensive melt is the northeast portion of the ice sheet. This region also has a very gentle slope and is at low elevation. Note that some summer melt effects are also suggested to occur within edges of the dry snow zones [27].

At the highest elevations, we observe that the summer melt has no impact on the microwave signatures since the class partitioning remains as that during cooler periods. This first look at our partition of the ice sheet shows good consistency with previous studies under winter conditions. It can thus represent a good indicator for long-term monitoring of climate change effects on the Greenland ice sheet related to melting and ablation. Analysis of the temporal variations in the classes' distribution is provided hereinafter.

\section{B. Finer Analysis of Temporal Variations}

With the large and coherent spatial structures being well identified, we perform a finer analysis of the temporal changes in the partitioning results. It shows that, as expected, melting as a function of time begins at the edges and progresses toward the interior of the ice sheet. Melt onset begins in a limited number of coastal pixels during April-May and begins to spread in June along the fringes of the ice sheet. In July, the melt extent rapidly increases, as seen in cycle 028-029 maps covering nearly the entire perimeter of the ice sheet. In these maps, we observe a high spatial inhomogeneity in the snow pack types, i.e., pixels in class 1 (dark blue), class 2 (light blue), and class 3 (green) are all mixed up with, however, a higher number of pixels in class 1 indicating bare ice or land. Such result reflects that the dominant signal comes from the surface rather than from the subsurface. Discrimination between classes 2 and 3 depends on the penetration depth; so, it is difficult during the melting period due to the presence of liquid water. The next cycle maps show that refreeze begins to occur on the ice sheet, and the areal extent affected by melt begins to steadily drop until mid- to late September. This is shown by the decrease in the pixel number plotted in dark blue and purple. This decrease is gradual throughout October [24], with the decrease in the extent of the green zones in the maps. During the cooling period, the differing penetration depths act to prolong the detection of melt until the subsurface snow has refrozen, as seen from cycles 030-032. For example, the passing of a cold front, which may act to refreeze the surface while the subsurface remains wet, will not be classified as "dry (in fact, as class 2 in the south portion)" until the snow is frozen at greater depths. With fall, the variability in these areas is gradually reduced with progressive change in class attribution from class 1 (ablation or land) to class 2 (percolation zone), with a crossing in class 3 (wet snow zone) due to the move in microwave signatures linked to the snow pack characteristics change. This change in class reflects the change in microwave signatures and is more comprehensively illustrated with the diagram in Fig. 4. The presence of wetness results in limited penetration of the microwave signals into the snow and firn. The subsurface conditions become camouflaged due to the increased surface reflection and absorption within the surface layers. By early winter, the seasonal cold temperature wave has sufficiently deeply penetrated to permit the radar waves to penetrate the upper layers of snow and firn. The microwave signatures remain stable throughout the winter, allowing the discrimination of the different snow pack regions, as described by Benson.

We do not have, at this time, interpretation for class 6 in purple. It seems to be associated to some melting spread within the dry snow zone during summer, as shown by the good agreement of our map with [17, Fig. 5]. They showed the map of the number of melt days, as derived from QuikSCAT in 2002. Melt can occur at locations within the dry snow zone. Its delineation is easier to visualize during summer periods, where its extent is the largest. However, this class is also observed during winter over a much restricted area located between the global dry snow zone and the percolation zone, where, however, no melt is likely to occur or form the transition region between the two zones. It might suggest the presence of a crust ice layer formed from a short and low intense summer melt that does not release water that would percolate but the melting is enough to moisturize the surface of snow and change its microwave signatures. Fig. 5 summarizes the described seasonal variability in the classes' extent with time.

As seen, particular snow pack characteristics can be grouped into a number of general snow facies classes from observed 


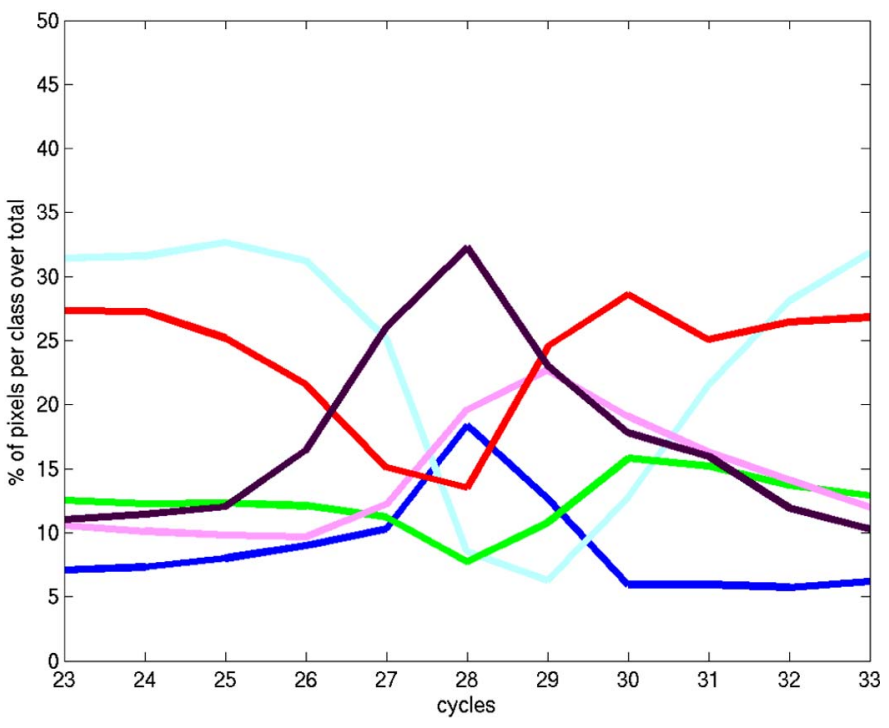

Fig. 5. Percentages of Greenland pixels per class with respect to the cycle number. The curves cover the whole year of 2004 and the correspondence between the cycle and date is provided in Table I. The correspondence between classes and colors are as provided in the color bar in Fig. 3.

microwave signatures. Finally, here, we show an approach for mapping snow facies that might provide a consistent long-term assessment of the melt conditions on the ice sheet. Analysis over a longer time series of a few years will be the focus of future work. Our results confirm that the maximum melt occurs on the western coast, particularly in the southern part of the ice sheet, and that the areas that are most sensitive to melt variations are the lower elevation regions of the ice sheet, as observed by previous studies on Greenland snowmelt [17]-[25]. Moreover, we show that different regions within a global dry snow zone can be separated based on snow morphology (i.e., grain size) and surface roughness related to the local wind field characteristics. The use of multiple sensors appears to improve the ability to identify different snow facies by combining the inherent strengths of each instrument.

\section{Discussion for Antarctic ICE Sheet}

Concerning Antarctica snow zone classification, Table V summarizes the statistical characteristics of the input parameters computed based on the two cycles used to normalize the data, i.e., 023 and 029. Results from the application of a sevenclass classifier solution on the time series of Envisat data for the whole year of 2004 are presented in Fig. 6. This sevenclass solution allows one to better catch the seasonal signal than other computed solutions (Figs. not shown). It displays larger contrasts between the winter and summer cycles, which seem to be more realistic in terms of seasonal variation in snow metamorphosis. This is more clearly visualized when looking at the positions of the class centers in the 4-D input space in the diagram in Fig. 7. Note that the associated values are provided in Table VI. It illustrates the principal characteristics of each class in terms of dominant microwave signatures. The classes in light blue and orange show stable geographical locations and extents throughout the year. Seasonal differences occur for the other classes. The two classes in purple and pink exhibit
TABLE $\mathrm{V}$

STATISTICAL INDICATORS (MEAN AND STANDARD DEVIATION) OF THE Four ENVISAT QuANTITIES. THEY ARE COMPUTED OVER ANTARCTICA From THE DATA OF CYCLES 023 AND 029

\begin{tabular}{lcccc}
\hline & $\mathrm{x} 1=\mathrm{Ku} \sigma 0$ & $\mathrm{x} 2=\mathrm{TB} \_$avg & $\mathrm{x} 3=$ TB_ratio & $\mathrm{x} 4=(\mathrm{Ku}-\mathrm{S}) \sigma 0$ \\
& $(\mathrm{~dB})$ & $(\mathrm{K})$ & $(/)$ & $(\mathrm{dB})$ \\
\hline mean & 8.5433 & 190.0169 & -0.0147 & -0.6846 \\
std & 3.8460 & 23.0642 & 0.0153 & 2.3071 \\
\hline
\end{tabular}

differences related to brightness temperature variation, which is mostly linked to variations in temperature. The classes in dark blue, green, and red also show seasonal variations in location and extent.

This Antarctica classification result does not display snow zones as defined by Benson, in contrast with our results over Greenland. In fact, previous studies have shown that, in Antarctica, the extent of the wet snow zone is spatially insignificant [27]. It accounts for only a few percent of the ice sheet surface. It is mainly distributed in the northern part of the Antarctic Peninsula and on a few parts of the ice shelves. Moreover, the melting is relatively sparse and short-lived. Additionally, the cooling period takes a much longer time than the warming period. The majority of the coastal regions of the Antarctic continent only have narrow percolation zones, without developed wet snow zone. No superimposed bare ice zones in Benson's model were detected at the outer ring of the wet snow zone on the Antarctic Peninsula in previous studies. The dry snow zone dominates the Antarctic continent.

Interestingly, there is a strong topographic control on the class distribution extents when compared with maps of elevation and surface slope [11]. The classes separate the major wind and ice sheet drainage basins, which are related to the shape of the Antarctic ice sheet. Thus, our classification solution displays the partition of the ice sheet in terms of snow accumulation and/or snow drift redistribution patterns and snow layering as a consequence of the topographically influenced wind regime. A short description of typical snow pack properties for all classes is provided here. Note that such specifications are limited since the transition from one surface type to another is smooth or fuzzy. The spectrum of possible physical characteristics is large, even within one class.

Class 1 in dark blue is located along the crest line formed by the domes and ridges in the central East Antarctic Plateau. This region is characterized by dry snow, low accumulation $\left(<50 \mathrm{~kg} / \mathrm{m}^{2} / \mathrm{an}\right)$, and very cold temperature during winter. The high ice thickness in this interior high plateau region leads to a smooth region with negligible aligned roughness and isotropic backscatter since this region is characterized by the lack of directionality in the wind direction associated to light winds. This class 1 region becomes classified as class 6 in the summer period. Such change is suggested to be due to the increase in the temperature (air and surface), which affects and changes the morphological structure of the snow to form regular seasonal layering. Indeed, large relative separations in the $\nu_{2 i}$ and $\nu_{3 i}$ coordinates of their respective tie point are observed in Fig. 7. The difference in $\nu_{4 i}$ coordinates and the rapid switch between classes 1 and 6 may be interpreted as a densification effect, 

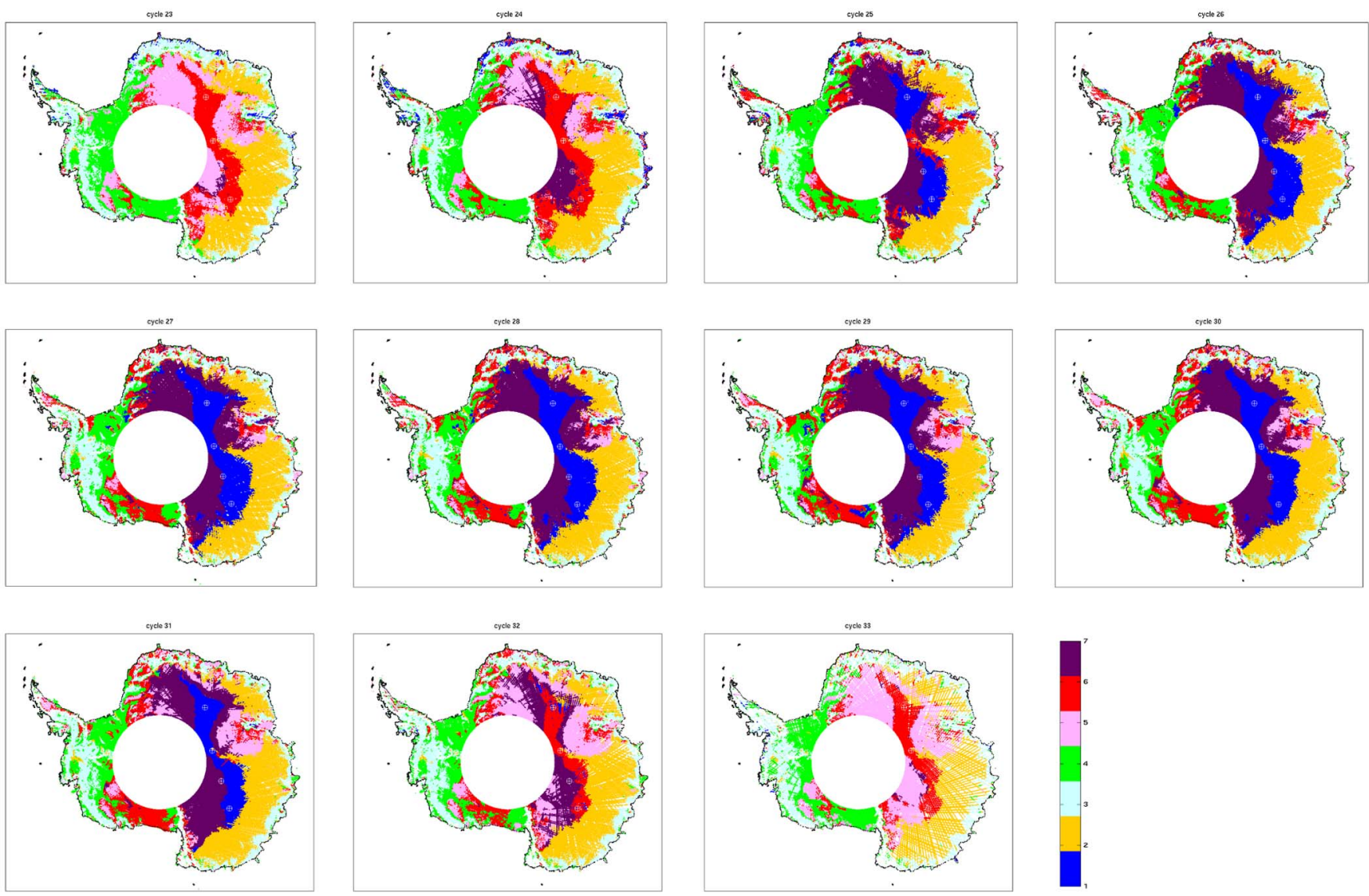

Fig. 6. Cycle summary of the Envisat snow classification algorithm based on seven classes over Antarctica. It covers the whole year of 2004. Note that, even if the color scale is the same as that for Greenland, the classes designed with the same number and color do not have the same dominant microwave features since the two classifiers were independently developed from each other.

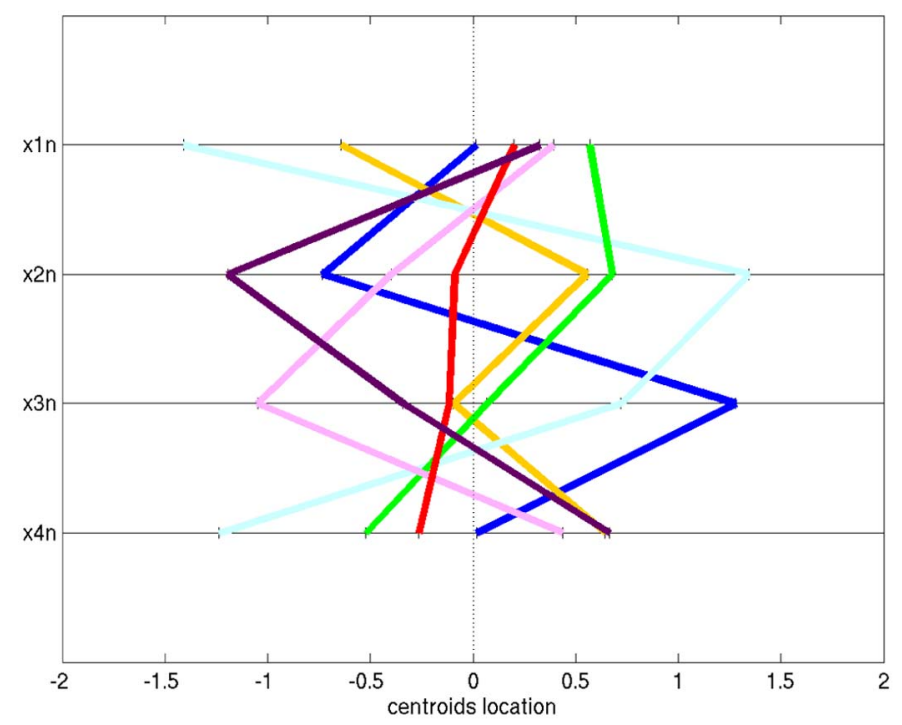

Fig. 7. Synoptic view of the tie-point locations. Each horizontal line represents the normalized variation interval of an input parameter. The segments in a given color connected the coordinates of a single tie point. The correspondence between classes and colors are as provided in the color bar in Fig. 6.

because the densification process is known to rapidly occur. Changes in $\nu_{4 i}$ might come from surface roughness features, but the wind is known to not affect much this central part of the ice sheet.
TABLE VI

TIE-Point Locations In THE 4-D Normalized SpaCE OF THE INPUT PARAMETERS FOR THE ENVISAT SNOW CLASSIFIER OVER ANTARCTICA. This Solution Is Composed of SEVEn Classes

\begin{tabular}{lccccc}
\hline & color & $\boldsymbol{v}_{\mathbf{1 i}}$ & $\mathbf{v}_{2 \mathrm{i}}$ & $\boldsymbol{v}_{3 \mathrm{i}}$ & $\mathbf{v}_{4 \mathrm{i}}$ \\
\hline Class 1 & dark blue & 0.0170 & -0.7316 & 1.2813 & 0.0189 \\
Class 2 & orange & -0.6415 & 0.5564 & -0.0955 & 0.6446 \\
Class 3 & light blue & -1.4096 & 1.3451 & 0.7214 & -1.2365 \\
Class 4 & green & 0.5686 & 0.6792 & 0.0672 & -0.5209 \\
Class 5 & pink & 0.3930 & -0.3994 & -1.0485 & 0.4361 \\
Class 6 & red & 0.2013 & -0.0889 & -0.1178 & -0.2634 \\
Class 7 & purple & 0.3252 & -1.1955 & -0.3414 & 0.6662 \\
\hline
\end{tabular}

Class 2 in orange corresponds to lower altitude coastal regions of East Antarctica that are affected by strong katabatic winds flowing downslope toward coasts and carve the surface making significant microrelief, such as sastrugi [57]. In these areas, the accumulation rate is higher and participates in increasing the surface roughness [58] composed of erosional and depositional features. Directional anisotropy of the backscatter is also observed and is associated with a preferred orientation of linear structures and roughness elements that are aligned parallel to the prevailing wind direction. The surface exhibits variable slope, it is wind glazed, and the layering is irregular. 
The class 2 region is stable in the location all year long. This indicates that the dominant microwave signatures that characterize this class come from surface roughness rather than temperature, as confirmed by the diagram in Fig. 7.

In the central east part of the ice sheet, regions indicated as forming class 7 in purple and located on the western side from the domes and ridges line are characterized by low snow accumulation $\left(<100 \mathrm{~kg} / \mathrm{m}^{2} / \mathrm{an}\right)$ and moderate winds. The latter induces low surface roughness due to wind erosion and redistribution of surface snow. This decrease in the katabatic wind flow intensity and increase in the directional variability is due to the interior topography configuration farther away from coastal depressions. The katabatic flow is less developed because of the weaker surface layer temperature deficit and is less channeled. The class 7 region becomes classified as class 5 (in pink) in the summer cycles due to seasonal changes in temperature. The transition from one class to the other is obvious in the map of cycle 024 (during fall) and the maps of cycles 031 and 032 (in the spring transition). High summer temperatures alter the snow pack characteristics in a way that contributes to change the classification at different locations. This is visible mainly in the interior ice sheet, because seasonal temperature amplitude is greatest toward the high interior of the continent, as seen with station surface temperature data [59]. Note that the transition in this region between classes 7 and 5 starts before the switch between classes 1 and 6 in the nearby flatter region, suggesting a more direct effect related to temperature change.

Areas associated to class 3 in light blue are stable in location over the year and are associated to marginal zones of the ice sheet with steep slope and mountainous terrains, such as the massive Transantarctic Mountain chain. However, this class also includes regions in the southwestern part of the West Antarctic ice sheet (i.e., the Ellsworth Land and Palmer Land) that are associated with very high accumulation $\left(>200 \mathrm{~kg} / \mathrm{m}^{2} / \mathrm{an}\right)$, small snow grain, and compact snow pack.

Finally, if the two main flat ice shelves, i.e., the Ross Ice Shelf and the Filchner-Ronne Ice Shelf, are identified as belonging to class 4 (in green) in the summer period, asymmetric behavior is observed during the freezing winter season, where the Ross Ice Shelf is in class 6 and the Filchner-Ronne Ice Shelf remains in class 4 . As seen, depending on season, the class 6 in red is associated with different flat regions, which display similar microwave signatures at different times. The difference in the classification of these two areas during winter is suggested to be attributable to the much higher snow accumulation rate on the Filchner-Ronne Ice Shelf than that on the Ross Ice Shelf [60]. The difference in penetration depth during winter and summer does not seem to have an impact on the classification of the microwave signatures over the Filchner-Ronne area since the microwave signatures only slightly vary, whereas the deeper penetration during winter in the Ross area seems to sense important subsurface elements. Another explanation is that melt occurs on this ice shelf. Indeed, Liu et al. [27] have classified the Ross Ice Shelf as a percolation zone, whereas the Filchner-Ronne Ice Shelf is set as a dry snow zone. Synthesis of the description of the seasonal variation in the classes' extent is provided in Fig. 8. Note that the curve associated to class 6

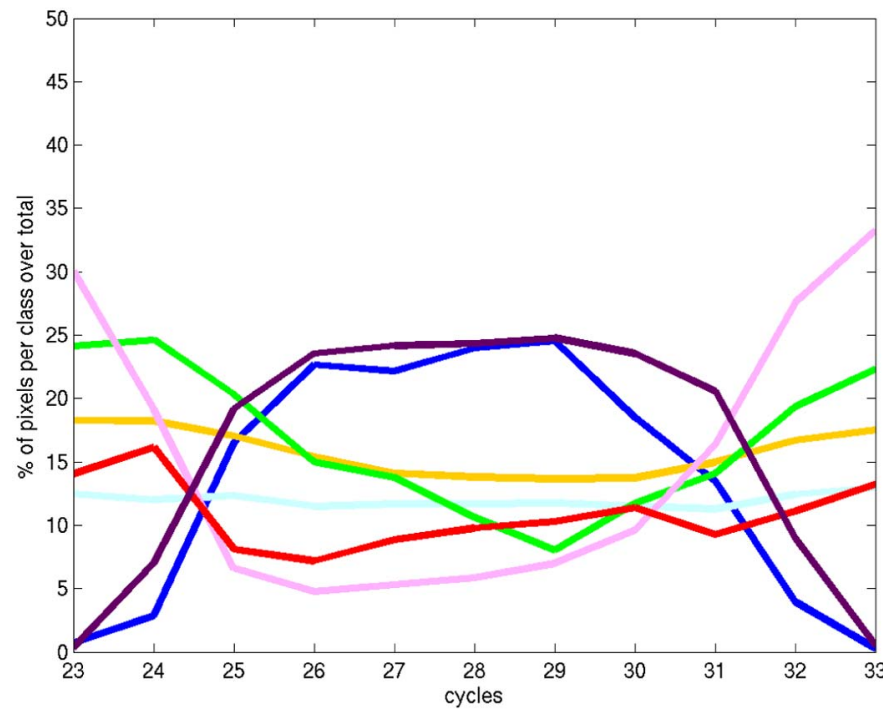

Fig. 8. Percentages of Antarctic pixels per class with respect to the cycle number over the whole year of 2004. The correspondence between classes and colors are as provided in the color bar in Fig. 6.

TABLE VII

SYNTHESIS OF THE CHARACTERISTICS OF SNOW PACK Classes for the ANTARCTICA PARTITION

\begin{tabular}{|c|c|c|c|}
\hline Class & Color & Physical properties & $\begin{array}{c}\text { Temporal } \\
\text { characteristic }\end{array}$ \\
\hline 1 & dark blue & $\begin{array}{l}\text { domes and ridges location / } \\
\text { low accumulation / } \\
\text { no wind / flat surface }\end{array}$ & only during winter \\
\hline 2 & orange & $\begin{array}{l}\text { high accumulation / } \\
\text { strong wind / } \\
\text { variable slope }\end{array}$ & rather stable yearlong \\
\hline 3 & light blue & $\begin{array}{l}\text { high accumulation / } \\
\text { steep slope (margins) }\end{array}$ & rather stable yearlong \\
\hline 4 & green & $\begin{array}{l}\text { ice shelves / } \\
\text { flat surface }\end{array}$ & $\begin{array}{l}\text { yearlong for Filchner } \\
\text { Roone / Ross in } \\
\text { summer only }\end{array}$ \\
\hline 5 & pink & $\begin{array}{l}\text { low accumulation / } \\
\text { moderate wind }\end{array}$ & $\begin{array}{l}\text { only during summer / } \\
\text { becomes class } 7 \text { in } \\
\text { winter }\end{array}$ \\
\hline 6 & red & $\begin{array}{l}\text { no wind over domes and } \\
\text { ridges location / } \\
\text { flat surface }\end{array}$ & $\begin{array}{l}\text { change in geographic } \\
\text { location between } \\
\text { winter and summer }\end{array}$ \\
\hline 7 & purple & $\begin{array}{l}\text { low accumulation / } \\
\text { moderate wind }\end{array}$ & $\begin{array}{l}\text { only during winter / } \\
\text { becomes class } 5 \text { in } \\
\text { summer }\end{array}$ \\
\hline
\end{tabular}

(in red) is not interpretable in this plot due to change in geographic locations between the summer and winter periods. A short synthesis of the description of the principal characteristics for all classes is provided in Table VII.

The present classification approach thus principally highlights different regions within the dry snow zone. Such results illustrate the large potential of Envisat measurements for polar ice sheet studies. The classification algorithm yields maps with spatial snow facies distributions that are reasonable with expectations when general Antarctic background characteristics are considered. Within the spatially extensive and continuous dry snow zone, the snow accumulation rate and densification [16] are seen as a key factor that determines the morphological structure of the snow pack, along with air temperature, wind, and local topography. The approach proposed here provides 
a simple and efficient means for mapping different Antarctic snow facies diagenetic and to monitor changes that are occurring due to seasonal and/or metamorphic processes. Locally, snow metamorphism and the resulting stratigraphy of the snow and firn are principally influenced by the thermal regime during seasonal change. During winter or summer, there are distinctive contrasts between the West and East Antarctic snow classes.

Application of these signature statistics for other Envisat years might help to exhibit trends in the environmental forcing, such as temperature, snow accumulation, and wind pattern. The results, while far from being comprehensively validated, appear consistent with actual knowledge on the ice sheet state. The snow facies indicator, as previously defined, might be a promising indicator of climate change impact on the Antarctic ice sheet. A complementary line of future research is the extension of the interpretation of the results from a "hard" to a "fuzzy" way by using the subclass definition, i.e., when membership degree values are comparable between two classes, indicating an ambiguous or mixed-class situation, along with the dominant classes described in this paper.

\section{CONCLUSION}

This paper has combined measurements from two satellite sensors, i.e., RA-2 and MWR onboard the Envisat platform. The nadir-looking dual-frequency coregistered data from the two instruments are used to describe and classify the two polar ice sheets snow pack behavior. This approach represents a means to map facies boundary locations in a systematic way and to monitor their long-term spatial and temporal variations over the entire ice sheets. We provided here a view of the condition of the two ice sheets in 2004. We classify regions with similar nature of microwave signatures. The snow pack classes are determined by using a set of four parameters, which can be linked to the snow pack characteristics, such as snow grain size, density, subsurface layering, water content, or surface roughness. This difference in snow morphology is due to variable conditions in local climate, which is governed by local topography. We find that seven classes are suitable to partition Antarctica while a six-class solution seems more interesting for Greenland. These parameters are $\mathrm{Ku}$-band $\sigma_{0}, \mathrm{Ku}-\mathrm{S}$-band $\sigma_{0}$ difference, average of TB and ratio of TB. Although much effort has been done in previous studies to better understand the principles of microwave interaction with snow and ice, they are, so far, not fully explained in all their complexity. Within the snow pack, the accumulation rate is seen as a key factor that determines the morphological structure of the snow pack, along with air temperature, wind, local topography, and liquid water.

We have demonstrated the capability of Envisat RA-2 and MWR data for characterizing snow and ice facies on the two polar ice sheets. The two sensors used each add unique information to assist in separating the snow pack characteristics into different homogeneous regions. RA-2 is sensitive to surface roughness, volume inhomogeneities, and other scattering mechanisms that vary across different regions. MWR also contributes a great deal to the classification. As a passive instrument, the MWR snow pack signatures are more of a function of surface emissivity and dielectric properties than their active counterparts.

This approach can help for studying melt time period and extent, along with seasonal to interannual changes on the snow pack characteristics of Greenland and Antarctica. Note that we mapped the snow facies at the 35-day repeat cycle, but a finer resolution may be achieved based on the three-day subcycle of Envisat. The partition of the microwave signatures of the ice sheet snow pack enables delineation of different snow facies and might represent a useful tool for tracking the effects of climate change. Over Greenland, the presence of melt water, which is a consequence of thermal effects, changes the microwave signatures from the snow pack and induces changes in the delineation of the boundaries of the snow regions, as observed in the time series of maps. The algorithm yields results that are consistent with previous classifications and with our understanding of microwave behaviors over ice sheets. While over Antarctica, our results showed the partition of the ice sheet mainly into different dry snow zones and showed evidence that seasonal changes in snow metamorphism are principally influenced by thermal regime during the seasonal change. These thermal variations do not reach conditions where melting occurs, contrary to what happens on Greenland. Indeed, due to its lower latitude location, its mean annual surface temperatures are warmer than those on Antarctica, and small changes in the air temperature will result in larger effects on the snow pack.

The classification of the two ice sheets for the other years will be used in a comparative study with this base year to determine climatic changes with respect to this reference in future work. Observation of the effects of climate change through change in the microwave signal behavior might more easily be detected via the classification of the signatures and from a very longterm monitoring point of view. Through the years, only slight fluctuations of the class distribution are expected, with intraannual change being larger than the interannual change. The classification algorithm and methodology used here have the advantages of easy implementation, automatic processing, and straightforward and robust data classification. Operational implementation of this approach would routinely produce a large and consistent data set on a long-term basis for the purpose of monitoring climate change on the two ice sheets.

\section{ACKNOWLEDGMENT}

The authors would like to thank T. S. Moore, who kindly provided his FCM routines, which form the basis of the classification development, and the two anonymous reviewers for their suggested improvements to this paper.

\section{REFERENCES}

[1] F. Rémy, C. Brossier, and J. F. Minster, "Intensity of satellite radaraltimeter return power over continental ice: A potential measurement of katabatic wind intensity," J. Glaciol., vol. 36, no. 123, pp. 133-142, 1990.

[2] F. Remy, P. Shaeffer, and B. Legresy, "Ice flow physical processes derived from the ERS-1 high-resolution map of the Antarctica and Greenland ice sheets," Geophys. J. Int., vol. 139, no. 3, pp. 645-656, Dec. 1999.

[3] J. Bamber and J. L. Gomez-Dans, "The accuracy of digital elevation models of the Antarctic continent," Earth Planet. Sci. Lett., vol. 237, no. 3/4, pp. 516-523, Sep. 2005. 
[4] H. J. Zwally, A. C. Brenner, J. A. Major, R. A. Bindscadler, and J. Marsh, "Growth of Greenland ice sheet: Measurement," Science, vol. 246, no. 4937, pp. 1587-1589, Dec. 1989.

[5] H. J. Zwally, A. C. Brenner, J. A. Major, R. A. Bindscadler, and J. Marsh, "Growth of Greenland ice sheet: Interpretation," Science, vol. 246, no. 4937, pp. 1589-1591, Dec. 1989.

[6] C. H. Davis and S. Sun, "Long-term thinning of the southeast Greenland ice sheet from Seasat, Geosat, and GFO satellite radar altimetry," IEEE Trans. Geosci. Remote Sens., vol. 1, no. 2, pp. 47-50, Apr. 2004.

[7] H. J. Zwally, M. B. Gioveninetto, J. Li, H. G. Cornjo, M. A. Beckley, A. C. Brenner, J. Saba, and D. Yi, "Mass changes of the Greenland and Antarctic ice sheets and shelves and contributions to sea-level rise: 1992-2002,” J. Glaciol., vol. 51, no. 175, pp. 509-527, Dec. 2005.

[8] F. Remy and J. F. Minster, "Precise altimetric topography in ice sheet flow studies," Ann. Glaciol., vol. 17, pp. 195-200, 1993.

[9] D. J. Wingham, "A method for determining the average height of a large topographic ice sheet from observations of the echo received by a satellite altimeter," J. Glaciol., vol. 41, no. 137, pp. 125-141, 1995.

[10] F. Remy, C. Ritz, and L. Remy, "Ice sheet flow features and rheological parameters derived from precise altimetric topography," Ann. Glaciol., vol. 23, pp. 277-283, 1996.

[11] A. C. Brenner, J. P. DiMarzio, and H. Jay Zwally, "Precision and accuracy of satellite radar and laser altimeter data over the continental ice sheets," IEEE Trans. Geosci. Remote Sens., vol. 45, no. 2, pp. 321-331, Feb. 2007.

[12] L. M. Ulander, "Airborne radar altimetry over the Greenland ice sheet," M.S. thesis, Univ. London, London, U.K., 1985.

[13] M. R. Drinkwater, "Radar altimetric studies of polar ice," Ph.D. dissertation, Univ. Cambridge, Cambridge, U.K., 1987.

[14] K. C. Partington, J. K. Ridley, C. G. Rapley, and H. J. Zwally, "Observations of the surface properties of the ice sheets by satellite radar altimetry," J. Glaciol., vol. 35, no. 120, pp. 267-275, 1989.

[15] P. Lacroix, B. Legrésy, R. Coleman, M. Dechambre, and F. Rémy, "Surface and subsurface properties of snow on the Amery Ice-Shelf using Envisat's dual-frequency altimeter," Remote Sens. Environ., no. 109, pp. 285-294, 2007.

[16] P. Lacroix, M. Dechambre, B. Legrésy, and F. Rémy, "Effects of snow surface microroughness on the altimetric signals over ice caps," Remote Sens. Environ., no. 112, pp. 1712-1729, 2008.

[17] S. V. Nghiem, K. Steffen, G. Neumann, and R. Huff, "Mapping of ice layer extent and snow accumulation in the percolation zone of the Greenland ice sheet," J. Geophys. Res., vol. 110, no. F2, p. F02 017, Jun. 2005. DOI: $10.1029 / 2004 J$ J000234

[18] C. S. Benson, "Stratigraphic studies in the snow and firn of Greenland ice sheet," CRREL, Hanover, NH, p. 93, Res. Report 70, 1962.

[19] D. G. Long and M. R. Drinkwater, "Greenland ice sheet surface properties observed by the Seasat-A scatterometer at enhanced resolution," J. Glaciol., vol. 40, no. 135, pp. 213-230, 1994

[20] M. R. Drinkwater, D. G. Long, and A. W. Bingham, "Greenland snow accumulation estimates from satellite radar scatterometer data," J. Geophys. Res., vol. 106, no. D24, pp. 33 935-33 950, 2001.

[21] V. Wismann, "Monitoring of seasonal snowmelt on Greenland with ERS scatterometer data," IEEE Trans. Geosci. Remote Sens., vol. 38, no. 4, pp. 1821-1826, Jul. 2000

[22] I. S. Ashcraft and D. G. Long, "Comparison of methods for melt detection over Greenland using active and passive microwave measurements," Int. J. Remote Sens., vol. 27, no. 12, pp. 2469-2488, Jun. 2006.

[23] R. S. Fausto, C. Mayer, and A. P. Ahlstrom, "Satellite-derived surface type and melt area of the Greenland ice sheet using MODIS data from 2000 to 2005," Ann. Glaciol., vol. 46, no. 1, pp. 35-42, Oct. 2007.

[24] W. Abdalati and K. Steffen, "Snowmelt on the Greenland ice sheet as derived from passive microwave satellite data," J. Clim., vol. 10, no. 2, pp. 165-175, Feb. 1997.

[25] W. Abdalati and K. Steffen, "Greenland ice sheet melt extent: 1979-1999," J. Geophys. Res., vol. 106, no. D24, pp. 33 983-33988, 2001.

[26] A. W. Bingham and M. R. Drinkwater, "Recent changes in the microwave scattering properties of the Antarctic ice sheet," IEEE Trans. Geosci. Remote Sens., vol. 38, no. 4, pp. 1810-1820, Jul. 2000.

[27] H. Liu, L. Wang, and K. Jezek, "Automated delineation of dry and melt snow zones in Antarctica using active and passive microwave observations from space," IEEE Trans. Geosci. Remote Sens., vol. 44, no. 8, pp. 21522163, Aug. 2006.

[28] H. Rott, K. Sturm, and H. Miller, "Active and passive microwave signatures of Antarctic firn by means of field measurements and satellite data," Ann. Glaciol., vol. 17, pp. 337-343, 1993.
[29] D. G. Long and M. R. Drinkwater, "Azimuth variation in microwave scatterometer and radiometer data over Antarctica," IEEE Trans. Geosci. Remote Sens., vol. 38, no. 4, pp. 1857-1870, Jul. 2000.

[30] J. D. Flach, K. C. Partington, C. Ruiz, E. Jeansou, and M. R. Drinkwater, "Inversion of the surface properties of ice sheets from satellite microwave data," IEEE Trans. Geosci. Remote Sens., vol. 43, no. 4, pp. 743-752, Apr. 2005.

[31] B. Legresy and F. Remy, "Using the temporal variability of the radar altimetric observations to map surface properties of the Antarctic ice sheet," J. Glaciol., vol. 44, no. 147, pp. 197-206, 1998.

[32] H. J. Zwally and S. Fiegles, "Extent and duration of Antarctic surface melting," J. Glaciol., vol. 40, no. 136, pp. 463-476, 1994.

[33] J. Benveniste, M. Roca, P. Vincent, G. Levrini, S. Baker, O.-Z. Zanife, and C. Zelli, "The Envisat radar altimetry mission: RA-2, MWR, DORIS and LRR," in ESA Bull., vol. 105, 2001, pp. 67-76.

[34] J. Benveniste, S. Baker, O. Bombaci, C. Zeli, P. Venditti, O.-Z. Zanife, B. Soussi, J.-P. Dumont, J. Stum, and M. Pilar Milagro-Perezin "Envisat RA-2/MWR product handbook," Eur. Space Agency, Frascati, Italy, PO-TN-ESR-RA-0050, 2002. [Online]. Available: http://envisat.esa. int/dataproducts/ra2-mwr/CNTR.htm

[35] A. J. Gow, "On the rates of growth of grains and crystals in south polar firn," J. Glaciol., vol. 8, no. 53, pp. 241-252, 1971.

[36] S. C. Colbeck, "Snow-crystal growth with varying surface temperatures and radiation penetration," J. Glaciol., vol. 35, no. 119, pp. 23-29, 1989.

[37] K. Steffen, "Surface energy exchange at the equilibrium line on the Greenland ice sheet during onset of melt," Ann. Glaciol., vol. 21, pp. 13-18, 1995.

[38] K. C. Partington, "Discrimination of glacier facies using multi-temporal SAR data," J. Glaciol., vol. 44, no. 146, pp. 42-53, 1998.

[39] H. J. Zwally, W. Abdalati, T. Herring, K. Larson, J. Saba, and K. Steffen, "Surface melt-induced acceleration of Greenland ice sheet flow," Science, vol. 297, no. 5579, pp. 218-222, Jul. 2002.

[40] V. R. Wismann and K. Boehnke, "Monitoring snow properties on Greenland with ERS scatterometer and SAR," Eur. Space Agency Spec. Publ., pp. 857-862, 1997. ESA SP-414.

[41] S. V. Nghiem, K. Steffen, R. Kwok, and W. Y. Tsai, "Detection of snowmelt regions on the Greenland ice sheet using diurnal backscatter change," J. Glaciol., vol. 47, no. 159, pp. 539-547, 2001.

[42] H. Rott, G. Domik, C. Maetzler, H. Miller, and K. G. Lenhart, "Study on use and characteristics of SAR for land snow and ice applications," Institut fur Meteorologie und Geophysik, Universitat Innsbruck, Innsbruck, Austria, ESA Contract Report, 5441/83/D/IM(SC), 1985.

[43] H. J. Zwally, "Microwave emissivity and accumulation rate of polar firn," J. Glaciol., vol. 18, no. 79, pp. 195-215, 1977.

[44] D. P. Winebrenner, E. J. Steig, and D. P. Schneider, "Temporal covariation of surface and microwave brightness temperatures in Antarctica, with implications for the observation of surface temperature variability using satellite data," Ann. Glaciol., vol. 39, pp. 346-350, 2003.

[45] G. Macelloni, M. Brogioni, P. Pampaloni, and A. Cagnati, "Multifrequency microwave emission from the Dome-C area on the East Antarctic plateau: Temporal and spatial variability," IEEE Trans. Geosci. Remote Sens., vol. 45, no. 7, pp. 2029-2039, Jul. 2007. DOI: 10.1109/TGRS.2007.890805.

[46] C. A. Shuman, R. B. Alley, S. Anandakrishnan, J. W. C. White, P. M. Grootes, and C. R. Stearns, "Temperature and accumulation at the Greenland Summit: Comparison of high-resolution isotope profiles and satellite passive microwave brightness temperature trends," J. Geophys. Res., vol. 100, no. D5, pp. 9165-9177, 1995.

[47] S. Surdyk and M. Fily, "Comparison of the microwave spectral signature of the Antarctic ice sheet with ground traverse data," Ann. Glaciol., vol. 17, pp. 161-166, 1993.

[48] I. S. Ashcraft and D. G. Long, "Observation and characterization of radar backscatter over Greenland," IEEE Trans. Geosci. Remote Sens., vol. 43, no. 2, pp. 1-13, Feb. 2005

[49] B. Legrésy, F. Rémy, F. Papa, M. Van den Bossche, and O. Z. Zanife, "Envisat radar altimeter measurements over continental surfaces and ice caps using the ICE-2 retracking algorithm," Remote Sens. Environ., vol. 95, no. 2 , pp. $150-163$, Mar. 2005.

[50] F. Wang, "Fuzzy supervised classification of remote sensing images," IEEE Trans. Geosci. Remote Sens., vol. 28, no. 2, pp. 194-201, Mar. 1990.

[51] T. S. Moore, J. W. Campbell, and H. Feng, "A fuzzy logic classification scheme for selecting and blending satellite ocean color algorithms," IEEE Trans. Geosci. Remote Sens., vol. 39, no. 8, pp. 1764-1776, Aug. 2001.

[52] D. Vandemark, H. Feng, B. Chapron, N. Tran, and B. Beckley, "Use of fuzzy logic clustering analysis to address wave impacts on altimeter sea level measurements-Part II: Results status," Proc. Poster Ocean 
Surf. Topography Sci. Team Meeting, Venice, Italy, 2006. [Online]. Available: http://www.aviso.oceanobs.com/documents/swt/posters2006/ vandem ark.pdf

[53] J. Bezdek, Pattern Recognition With Fuzzy Objective Function Algorithms. New York: Plenum, 1981.

[54] L. K. Barlow, J. C. Rogers, M. C. Serreze, and R. G. Barry, "Aspects of climate variability in the North Atlantic sector: Discussion and relation to the Greenland Ice Sheet Project 2 high-resolution isotopic signal," J. Geophys. Res., vol. 102, no. C12, pp. 26333-26344, 1997.

[55] I. S. Ashcraft and D. G. Long, "Relating microwave backscatter azimuth modulation to surface properties of the Greenland ice sheet," J. Glaciol., vol. 52 , no. 177 , pp. $257-266,2006$.

[56] A. Ohmura and N. Reeh, "New precipitation and accumulation maps for Greenland," J. Glaciol., vol. 37, no. 125, pp. 140-148, 1991.

[57] F. Rémy, M. Ledroit, and J. F. Minster, "Katabatic wind intensity and direction over Antarctica derived from scatterometer data," Geophys. Res. Lett., vol. 19, no. 10, pp. 1021-1024, 1992.

[58] D. H. Bromwich, T. R. Parish, and C. A. Zorman, "The confluence zone of the intense katabatic winds at Terra Nova Bay, Antarctica, as derived from airborne sastrugi surveys and mesoscale numerical modeling," J. Geophys. Res., vol. 95, no. D5, pp. 5495-5509, 1990.

[59] J. C. Comiso, "Variability and trends in Antarctic surface temperatures from in-situ and satellite infrared measurements," J. Clim., vol. 13, no. 10, pp. 1674-1696, May 2000.

[60] M. B. Giovinetto and H. J. Zwally, "Spatial distribution of net surface accumulation on the Antarctic ice sheet," Ann. Glaciol., vol. 31, no. 1, pp. 171-178, Jan. 2000.

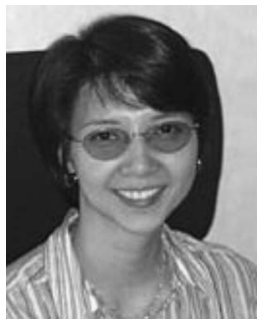

Ngan Tran received the Ph.D. degree in physical methods in remote sensing from the Universite Pierre et Marie Curie, Paris, France, in 1999.

From 2000 to 2002, she was a Research Scientist with Raytheon ITSS, NASA/GSFC/Wallops Flight Facility, where she worked on TOPEX/Poseidon and GFO radar altimeters and TOPEX radiometer data. In 2002, she joined Collecte Localization Satellites, Space Oceanography Division, Ramonville St-Agne, France, and was involved in the calibration/ validation activities of Jason-1 and Envisat radiometers. Her research interests include both active and passive microwave remote sensing. Her current research interests include the refinement of altimeter sea-state bias modeling using wave model outputs and the combination of different sensors to improve understanding of remote sensing observations and modeling.

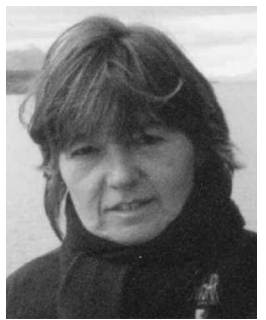

Frédérique Rémy obtained a thesis in astronomy in 1984 and a Ph.D. degree in glaciology in 1989 from the University of Toulouse, Toulouse, France.

She is a Specialist of remote sensing of the ice sheet and glacier for ice dynamics and mass balance, particularly of altimeter above the Antarctic ice sheet. She currently leads the Cryosphere Remote Sensing Group, Laboratoire d'Etude en Ghysique et Ocographie Spatiales, Toulouse, France. She is the author of about 60 peer-reviewed papers and two books.

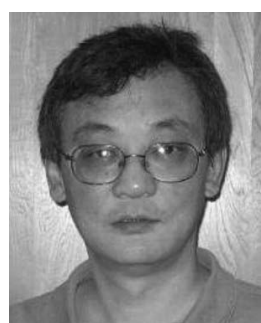

Hui Feng received the B.S. degree in radio physics from the East China Normal University (ECNU), Shanghai, China, in 1983 and the M.S. and Ph.D. degrees in oceanography from the University of New Hampshire, Durham, in 1996 and 2004, respectively.

From 1983 to 1993, he was a Research Associate with the Institute of Estuarine and Coastal Research, ECNU. From 1993 to 1999, he was a Graduate Research Assistant and focused on coastal oceanography and ocean color remote sensing. From March 2000 to November 2002, he was a Software Developer with Aprisma Management Technology, Portsmouth, NH. From November 2002 to May 2005, he joined the Goddard Earth Science Technology Center, Hampton University, Hampton, VA, as a Research Associate, and worked on altimeter sea-state bias correction algorithm development by using global ocean wave modeling data. Since May 2005, he has been a Research Scientist with the Ocean Process Analysis Laboratory, University of New Hampshire. His research interests include ocean color inversion algorithm development; validation of satellite ocean color retrievals in coastal regions using in situ atmospheric and aquatic optical measurements; and, recently, modeling sea-state bias for altimeter range correction, and evaluation and application of altimeter data in coastal regions.

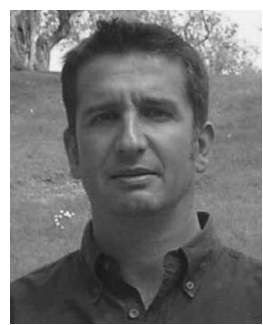

Pierre Féménias received the M.S. degree in engineering science from the Université Pierre et Marie Curie, Paris, France, in 1990.

From 1990 to 1994, he was a Research Engineer with the Laboratoire d'Etude en Géophysique et Océanographie Spatiales, Toulouse, France. Since 1994, he has been with the Ground Segment Department, Earth Observation Programs Directorate, European Space Agency (ESA), Frascati, Italy. He is currently in charge of the Altimetry System of the ESA Earth Observation operational missions (ERS, Envisat) and involved in the development of the future Cryosat-2 and Sentinel3 missions and GMES program. 